\title{
HIGH TEMPERATURE OXIDATION BEHAVIOUR OF HVOF SPRAYED Ni-30 MULLITE COATING ON MILD STEEL
}

\author{
Abhinay Rajput \\ Mechanical Engineering Department \\ NIT Calicut, Calicut, Kerala-673601, India
}

\begin{abstract}
The aim is to deposit Ni-Mullite (70:30 wt \%) coating on mild steel (MS) by high velocity oxy-fuel (HVOF) thermal spray process. The spraying conditions have been optimized to obtain an adherent coating of $\sim 110$ $\mu \mathrm{m}$ thickness. The coated specimens of dimensions $(20 \mathrm{~mm} \times 20 \mathrm{~mm})$ had been subjected to atmospheric oxidation at different temperatures of $5_{00}{ }^{\circ}, 7^{\circ}, \mathbf{9 0 0}^{\circ}$ and $1000^{\circ} \mathrm{C}$. Oxidation was performed for durations of 5,18 , 30 and 45 hours. The oxidized coatings have been characterized by X-Ray Diffraction (XRD) and Energy Dispersive Spectroscopy (EDAX). The oxidation rate has been studied in terms of mass gain with respect to time and temperature. It has been seen that till $\mathbf{7 0 0}^{\circ} \mathrm{C}$, there is negligible change in the mass gain and the oxide layer thickness. Beyond $700^{\circ} \mathrm{C}$ the mass gain and thickness of the oxide layer increases considerably up to a temperature of $1000^{\circ} \mathrm{C}$. The growth of the oxidized zone is seen to obey the parabolic law at high temperatures. Field Emission Scanning Electron Microscopy (FESEM) had been used to analyze the surface morphology. The as-coated specimen revealed the formation of porous nickel oxide with mullite particles distributed as fine nodular morphology. However, in oxidized specimens, formation of uniform grains containing aggregates of oxides of iron and that of wurtzite and haematite had been observed. This was also confirmed from EDAX analysis. The formation of iron oxide can be associated with the fact that iron diffuses outward to the surface resulting in oxide formation. This was reflected in the $X$-ray diffractogram as the highest intensity peaks in the oxidized specimen. This depicts that top surface has facilitated the oxidation of the base metal by the outward diffusion of iron atoms. Thus, to make this coating suitable for use at high temperatures, an interlayer that prevents inter-diffusion of elements between the substrate and coating is required.
\end{abstract}

\author{
Meenu Srivastava \\ Principal Scientist, Surface Engineering Division \\ CSIR-National Aerospace Laboratories, \\ Bangalore, Karnataka-560017
}

Keywords- Ni-Mullite, HVOF, FESEM, X-ray diffraction, Oxidation, EDAX

\section{INTRODUCTION}

In the age of development of next generation gas turbines that can withstand higher temperatures in the hot sections like turbine blades, nickel based super alloy have reached their limiting point of efficient performance against high temperatures and stresses. So, surface modification of turbines blades has been done by thermal spraying of refractory materials like YSZ, $\mathrm{Al}_{2} \mathrm{O}_{3}$, mullite by plasma spray and APS processes (Tsai H and Tsai P, 1995; Sarikaya et al.,2005; Khor and Gu, 2000; Kumar and Cietek, 2018; Ghosh and Mukharjee, 2016; Wu and Guo, 2010; Marcinauskas et al., 2010; An and Zhao, 2014) . Due to the high infrastructure cost involved in the APS process, effort is being made to develop these coatings by high velocity oxy fuel, HVOF process. However, it is a challenge to develop these coatings by HVOF process as the maximum obtainable temperatures are low as compared to the APS process (Lima and Marple, 2006). As a result, these refractory materials stay in partially melted state while striking the substrate due to their high melting point. Hence, it is required to add some metallic binders like nickel, cobalt and iron to these refractory powders to bind them together so as to obtain a coherent coating. Although very few reports are available on the development and performance of oxide based coatings by HVOF process (Prasad and Srivastava, 2017), the bulk composites of these coating materials have been investigated and reported to show changes during high temperature oxidation (Pham and Nanko, 2016; Erler and Jacob,2003; Citra and Chertihin, 1997; Nanko et al.,2005).

Hence, the present study is aimed at developing Ni-Mullite coating on mild steel by high velocity oxy-fuel thermal spraying process and studying its oxidation behavior. The oxidation behavior of the coating has been analyzed by subjecting them to different temperatures in the range of 500- 


\section{International Journal of Engineering Applied Sciences and Technology, 2019 \\ Vol. 4, Issue 4, ISSN No. 2455-2143, Pages 162-168 \\ Published Online August 2019 in IJEAST (http://www.ijeast.com)}

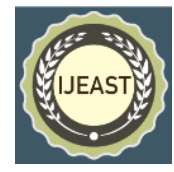

$1000^{\circ} \mathrm{C}$. The coating has also been extensively characterized to understand the phases formed w.r.t change in temperature.

\section{MATERIALS AND METHODOLOGY}

A powder blend of $70 \mathrm{wt} \%$ nickel and $30 \mathrm{wt} \%$ mullite was prepared by ball milling for 6 hours, then preheated at $70{ }^{\circ} \mathrm{C}$ for $4 \mathrm{hrs}$. The average particle size of the powder blend is $20 \pm 5 \mu \mathrm{m}$. Mild steel substrate of dimensions $100 \mathrm{~mm}$ X $100 \mathrm{~mm}$ $\mathrm{X} 2 \mathrm{~mm}$ was grit blasted with alumina of grit size 24 as a part of surface preparation prior to the HVOF spraying of the coating. A surface roughness obtained after the grit blasting is $\mathrm{Ra}=3$ microns as shown in fig. 1 .

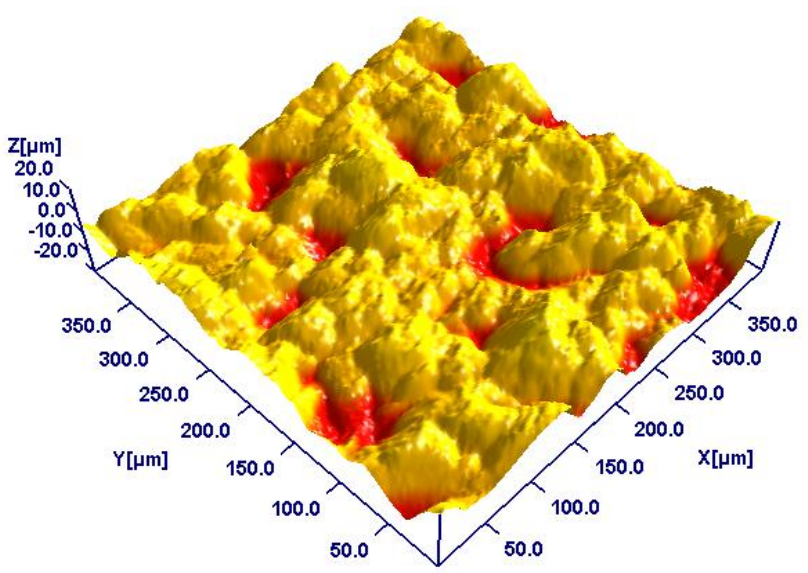

Fig. 1. Surface Roughness Profile of sand blasted Mild Steel substrate.

The sand-blasted MS specimen was ultrasonically cleaned using acetone and subjected to spraying. The HVOF spraying was performedusing HIPOJET-2700M spray gun procured from M/s Metallizing Equipment Company Pvt. Ltd., Jodhpur, India and using LPGas a fuel and nitrogen as the carrier gas for the powder. The spray parameters adopted during the sprayingof the coating are given in table 1.

\begin{tabular}{ll}
\hline Parameters & Values \\
\hline $\mathrm{O}_{2}$ pressure & $8-9 \mathrm{Kg} / \mathrm{Sq} \cdot \mathrm{cm}$ \\
$\mathrm{N}_{2}$ pressure & $6 \mathrm{Kg} / \mathrm{Sq} \cdot \mathrm{cm}$ \\
Air pressure & $6 \mathrm{Kg} / \mathrm{Sq} \cdot \mathrm{cm}$ \\
LPG pressure & $6-7.5 \mathrm{Kg} / \mathrm{Sq} \cdot \mathrm{cm}$ \\
LPG Flow Rate & $0.06 \mathrm{~m}^{3} / \mathrm{s}$ \\
$\mathrm{O}_{2}$ Flow Rate & $0.25 \mathrm{~m}^{3} / \mathrm{s}$ \\
Disk RPM (associated with powder flow rate) & $5 \mathrm{rpm}$ \\
Spray Angle & $90^{\circ}$ \\
Stand-off Distance & $250 \mathrm{~mm}$ \\
No. of Coating passes & 16 \\
Pitch & $5 \mathrm{~mm}$ \\
\hline
\end{tabular}

Table 1. Spray parameters for HVOF spraying of Ni-30Mullite coating on mild steel substrate.

The coated specimen was cut into 20 X 20 sq.mm to perform the oxidation studies under atmospheric conditions. The uncoated sides of the specimen were protected from oxidation, by applying a thick paste of $\mathrm{SiC}$. The oxidation studies were performed at temperatures of $500^{\circ} \mathrm{C}, 700^{\circ} \mathrm{C}$, $900^{\circ} \mathrm{C}$ and $1000^{\circ} \mathrm{C}$ for $5,18,30$ and 45 hours in a furnace chamber followed by furnace cooling. The oxidation behavior was studied by recording the mass gain of the oxidized specimens as a function of temperature and time. The oxidized specimens were mounted in trans-optic powder and subjected to grinding with emery of $600,800,1000,1200$ grit size followed by polishing with alumina paste of particle size 6 microns. The thickness of the coating and the oxide layer formed during oxidation was measured using LEICA-400 optical microscope. The phase identification of the specimen was done by X-ray diffractometer (Bruker D8) using $\mathrm{CuK}_{\alpha}$ radiation of wavelength $0.154 \mathrm{~nm}$. The surface morphology and composition of the as-coated and the oxidized specimens were analyzed using field emission scanning electron microscope (FESEM) affixed with energy dispersive spectrometer (EDAX) respectively.

ithm process is the inverse of the embedding process. It is assumed that the watermark as well as the see value is available at the receiver end to the authorized users.

The operation of channel separation is applied on the watermarked color image to generate its sub images, and then 2-level discrete wavelet transform is applied on the sub images to generate the approximate coefficients and detail coefficients.

\section{RESULT AND DISCUSSION}

The cross-sectional thickness of the as-deposited Ni-mullite coating is $110 \mu \mathrm{m}$. The surface of the coating was non-uniform due to the surface roughness which is of the order of Ra $7 \mu \mathrm{m}$. After subjecting the coating to high temperature, the thickness of the oxide layer is seen to increase significantly as shown in fig 2. The figure $2(a, b, c \& d)$ displays the thickness of the oxide layer formed typically at $900^{\circ} \mathrm{C}$ for durations of $5,18,30$ and 45 hours respectively. Severe cracks were observed while preparing the metallographic specimens of the coating oxidized at high temperatures, and this may be due to the brittle nature of the oxides formed during oxidation. The thickness of the overall coating along with the oxide layer is observed to be 216, 494, 954 and $1527 \mu \mathrm{m}$ for durations of 5, 18, 30 and 45 hours respectively. 


\section{International Journal of Engineering Applied Sciences and Technology, 2019 \\ Vol. 4, Issue 4, ISSN No. 2455-2143, Pages 162-168 \\ Published Online August 2019 in IJEAST (http://www.ijeast.com)}
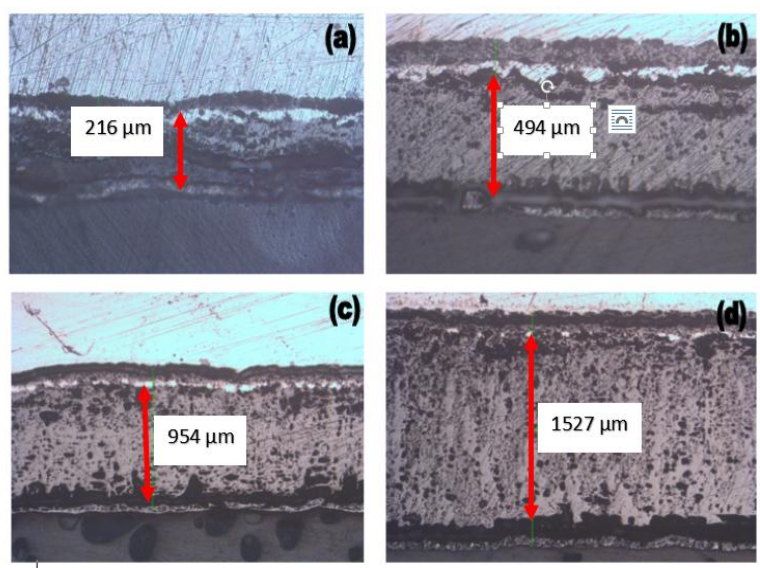

Fig. 2. Oxide scales formed in Ni-Mullite at $900^{\circ} \mathrm{C}$ for (a) 5 hr.; (b) $18 \mathrm{hr}$.; (c) $30 \mathrm{hr}$.; (d) $45 \mathrm{hrs}$. at 1000X magnification.

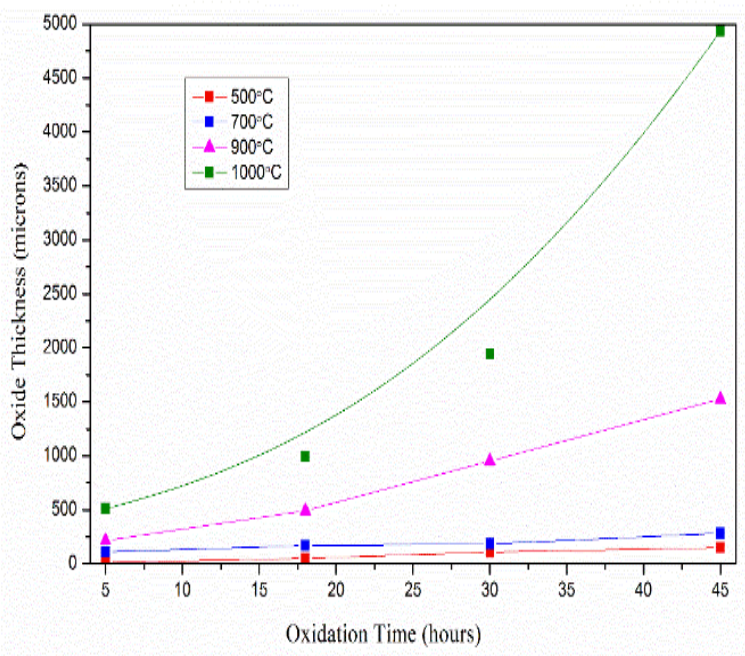

Fig. 3. Mass gain versus oxidation duration for oxidized NiMullite specimen for different temperature and duration.

Severe cracks were observed while preparing the metallographic specimens of the coating oxidized at high temperatures, and this may be due to the brittle nature of the oxides formed during oxidation. The thickness of the overall coating along with the oxide layer is observed to be 216,494 , 954 and $1527 \mu \mathrm{m}$ for durations of 5, 18, 30 and 45 hours respectively. The oxidation behavior expressed as oxide thickness at different temperatures and durations is depicted in fig 3. It is seen that till $700^{\circ} \mathrm{C}$, there is negligible change in the mass gain and the oxide layer thickness, but beyond $700^{\circ} \mathrm{C}$ the mass gain and thickness of the oxide layer increases considerably upto a temperature of $1000^{\circ} \mathrm{C}$. This suggests that during oxidation there is a change in the structure and composition of the phases resulting in an increase in the mass and thickness of the oxide layer. Inward diffusion of oxygen is the prime cause of mass gain (Srivastava and Muniprakash, 2014).

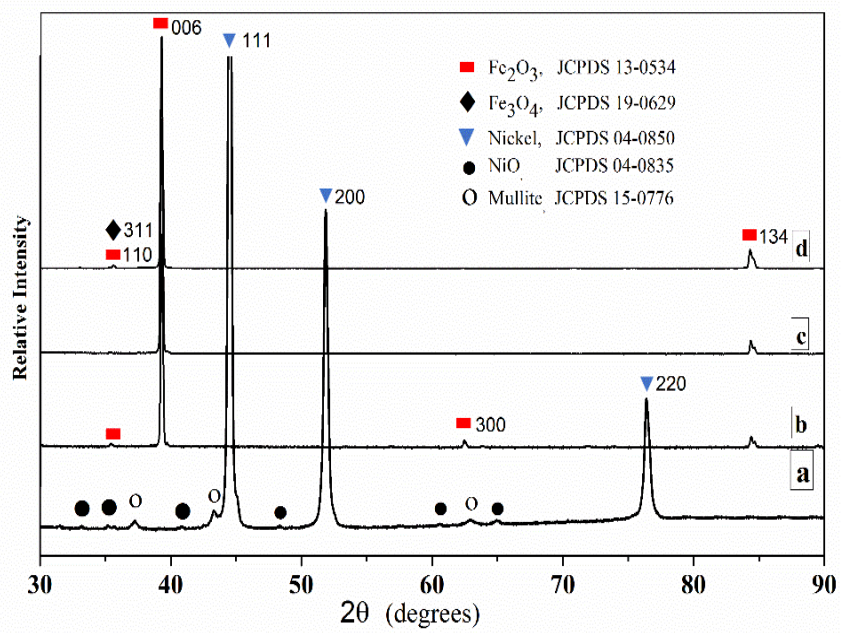

Fig. 4. XRD Diffractograms of the as-coated Ni-Mullite(a) and the Oxidized samples at $900^{\circ} \mathrm{C}$ for $30 \mathrm{Hrs}(\mathrm{b})$. and $1000^{\circ} \mathrm{C}$ for $18 \mathrm{Hrs}$.(c) and $30 \mathrm{Hrs}$.(d).

The X-ray diffractogram shown in fig $4 \mathrm{a}$ of the as-coated specimen reveals the presence of nickel oxide and mullite reflections. From FWHM data, The approx crystallite size of nickel is $31 \mathrm{~nm}$. However, the coating oxidized at $900^{\circ} \mathrm{C}$ and $1000^{\circ} \mathrm{C}$ for 18 and 30 hours shows the formation of only oxides of iron, and no reflections corresponding to mullite is seen. The crystallite size of the iron oxide is $77 \mathrm{~nm}$ at $900^{\circ} \mathrm{C}$ for a duration of 30hours. The crystallite size of iron oxide at $1000^{\circ} \mathrm{C}$ is $78 \mathrm{~nm}$ and $75 \mathrm{~nm}$ for durations of 18 and 30 hours respectively. The surface morphology of as-coated and oxidized Ni-mullite coatings is displayed in fig 5. The ascoated specimen shows formation of porous nickel oxide along with mullite particles distributed as fine nodular morphology (fig 5a). However, in the oxidized specimen's formation of uniform grains containing aggregates of oxides of iron and that of wurtzite and hematite are observed (fig 5b, c, d). EDAX data confirms that the surface of the oxidized specimens is rich in iron and oxygen in the requisite proportion as shown in table 2 . 

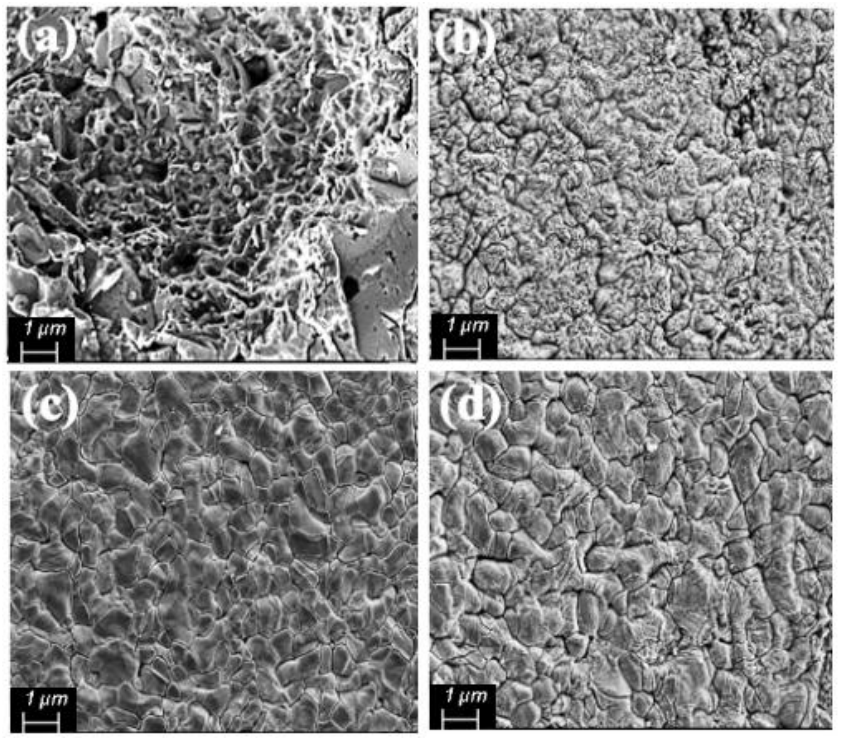

Fig. 5. Morphology of as-coated Ni-30mullite (a) and oxidized samples at $900^{\circ} \mathrm{C} \mathrm{(b)}$ and $1000^{\circ} \mathrm{C}$ for $18 \mathrm{Hrs}$.(c) and $30 \mathrm{Hrs}$.(d). at $10000 \mathrm{X}$.

\begin{tabular}{lllll}
\hline Elements(wt.\%) & Ni-30mullite & $\begin{array}{l}900^{\circ} \mathrm{C} \text { for } \\
30 \mathrm{Hrs} .\end{array}$ & $\begin{array}{l}1000^{\circ} \mathrm{C} \text { for } \\
18 \mathrm{Hrs} .\end{array}$ & $\begin{array}{l}1000^{\circ} \mathrm{C} \text { for } \\
30 \mathrm{Hrs} .\end{array}$ \\
\hline $\mathrm{O}$ & 13.35 & 23.41 & 25.87 & 22.12 \\
$\mathrm{Al}$ & 6.54 & - & - & - \\
$\mathrm{Si}$ & 1.88 & 1.16 & - & - \\
$\mathrm{Ni}$ & 78.24 & - & - & - \\
$\mathrm{Fe}$ & - & 75.43 & 74.13 & 77.88 \\
\hline
\end{tabular}

Table 2. Surface composition analysis of as-coated Ni30mullite and oxidized specimens.

The formation of iron oxide can be associated with the fact that iron diffuses outward to the surface and its oxide predominantly has highest intensity peaks in oxidized specimen. This depicts that top surface has facilitated the oxidation of the base metal by the outward diffusion of iron atoms, which also justifies the increased oxidation zone thickness with increase in the duration of oxidation as compared to original coating thickness. To get a better insight of the oxide zone, the FESEM analysis across the cross-section of the $900^{\circ} \mathrm{C}, 5$ hours oxidized specimen was performed. It revealed the formation of three different morphologies across the cross-section (fig 6).

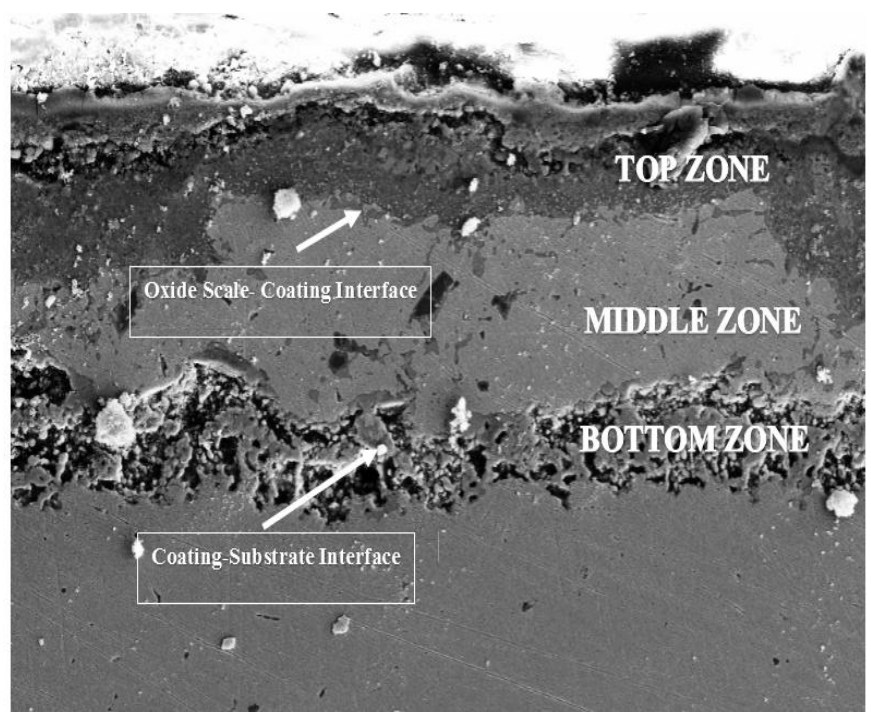

Fig. 6. Morphology of the oxidation zone of the Ni-30mullite oxidized $900^{\circ} \mathrm{C}, 5$ hours at $1000 \mathrm{X}$ magnification.

The top zone or surface layer comprises of the oxide scale formed by the outward diffusion of the base metal (iron) atoms and its reaction with oxygen and forming iron oxide. The middle zone consists of pores while, the bottom zone i.e. the interface between the substrate and the coating consisted of interconnected pores to form big voids. EDAX analysis of these three zones was performed and the compositional variation is shown in fig 7 . It is observed that the surface layer has low percentage of nickel and high percentage of iron while, the middle zone is enriched with nickel and less of iron and the third zone follows the same trend as that of the first. With such a variation in the elemental composition, it is indicated that at high temperatures, chemical potential between oxygen rich atmosphere and coating containing $\mathrm{MO}$ and $\mathrm{A}_{2} \mathrm{O}_{3}$ type of elements having oxygen deficiency, during oxidation act as a driving force for inward anion diffusion of oxygen ions. To maintain electrical neutrality there is outward cationic diffusion of ferrous ions through the porous network of the Ni30Mullite coating. As the ferrous atoms leave their lattice sites, it leaves a vacancy defect. With mass diffusion of ferrous atoms, these vacancy defects aggregate to form voids and cracks. This phenomenon started at the interface of the coating and substrate i.e. at the interface of middle and bottom zone. Nickel is present in oxide form in as-coated condition, it undergoes a little two-sided diffusion from middle zone to top and bottom zone. Mullite remains inert to oxidation and decomposition, which is evident by the TGA analysis of the Ni-30Mullite coating. 


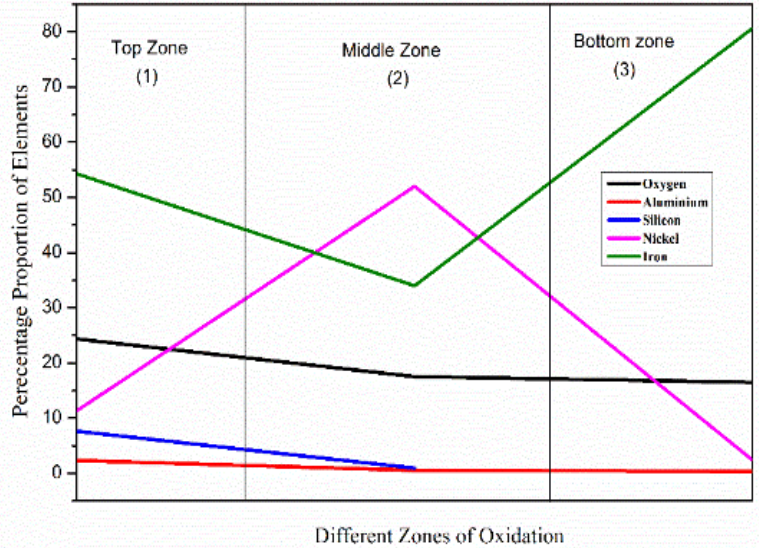

Fig. 7. Elemental composition variation along different oxidation zones of oxidized $\mathrm{Ni}-30$ mullite sample $\left(900^{\circ} \mathrm{C}, 5\right.$ hours).

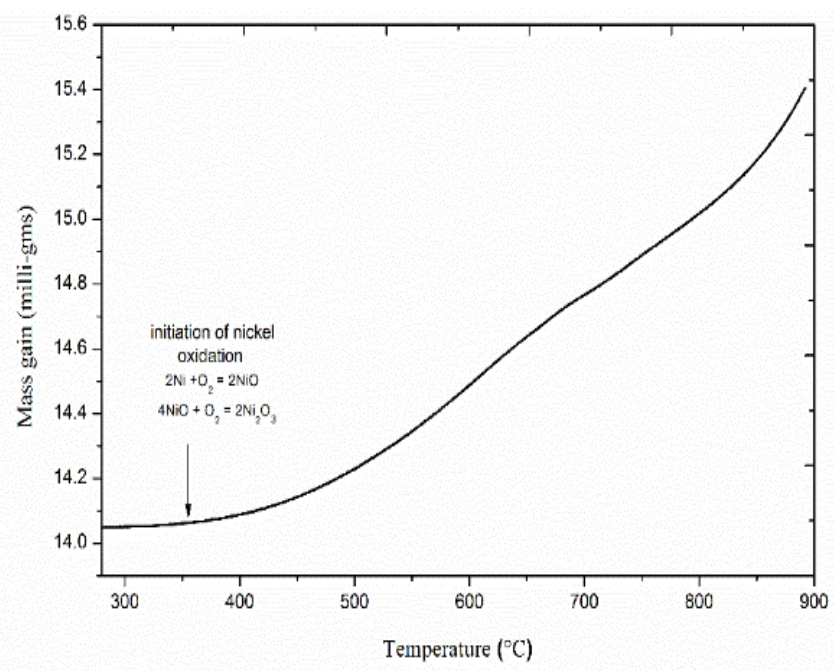

Fig. 8. TGA analysis of the Ni-30Mullite coating with air as a medium.

The curve indicates that only nickel oxide is forming secondary oxides $\left(\mathrm{Ni}_{2} \mathrm{O}_{3}\right)$ (fig 8) (Citra and Chertihin, 1997), allowing base metal iron to participate in oxidation-induced diffusion. In addition, the higher oxidation tendency of iron compared to nickel allows it to undergo outward diffusion. Inward Diffusion of oxygen from surrounding atmosphere is given as:

$$
\frac{2}{3} A+O^{2-}+2 h=\frac{1}{3} A_{2} O_{3}
$$

which is assisted by inward diffusion of holes formed intrinsically. This also supports inward diffusion of nickel by the equation:

$$
M O+\frac{2}{3} A+2 h=\frac{1}{3} A_{2} O_{3}+M^{2+}
$$

By reaction (1), oxygen penetrates through the surface oxide layer and pushes deep into the substrate. In equations (1) and (2), A and $\mathrm{M}$ represents nickel (Ni) and iron (Fe) respectively. It has hematite $\left(\mathrm{Fe}_{2} \mathrm{O}_{3}\right)$ and wurtzite $(\mathrm{FeO})$ closest to substrate, some amount of magnetite is also present as fine nodular particles (Grosvenor and Kobe, 2005). Both these oxides undergo similar type of reaction (i.e. eqn $1 \& 2$ ). This type of reaction results in the generation of cracks \& voids. This aspect has been described in detail by (Nanko et al.,2005). These vacancies and defects get segregated resulting in the formation of big cracks. Due to upward diffusion of ferrous ions, top surface gets piled up with oxide of iron resulting in development of new oxide interface over the old one resulting in an increase in the oxide zone thickness. In terms of point defects, vacancies created by iron atoms are accommodated by nickel atoms but most of them remain vacant, which causes piling up of these vacancy defects along with the inward diffusion of oxide ions. These aggregate together forming cracks and pores visible in the bottom zone as shown in fig 9.

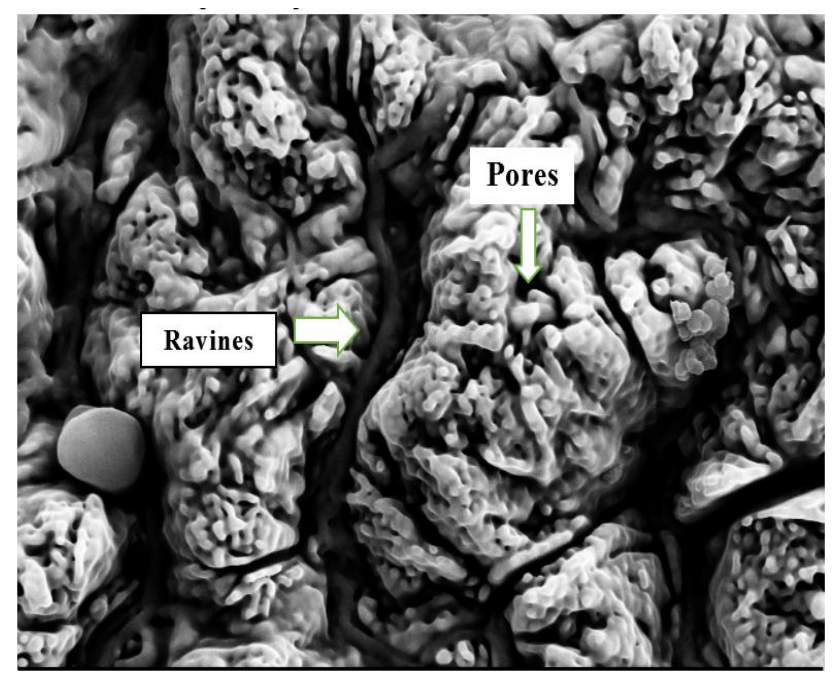

Fig. 9. Cracks and Pores get aggregated to form interconnected ravines providing easy passage to base metal ferrous ions for upward diffusion. 


\section{International Journal of Engineering Applied Sciences and Technology, 2019 \\ Vol. 4, Issue 4, ISSN No. 2455-2143, Pages 162-168 \\ Published Online August 2019 in IJEAST (http://www.ijeast.com)}

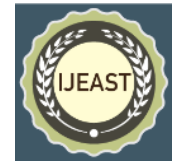

\section{CONCLUSION}

Phenomena of ion diffusion and aggregation of defects has been elaborately discussed by (Nanko et al.,2005). By analytical methods, square of mass gain due to oxidation, can be correlated with oxidation time to obtain the parabolic rate constant Kp (Pieraggi et al., 1987; Monceau and Pieraggi, 1998 ) as displayed in fig 10.

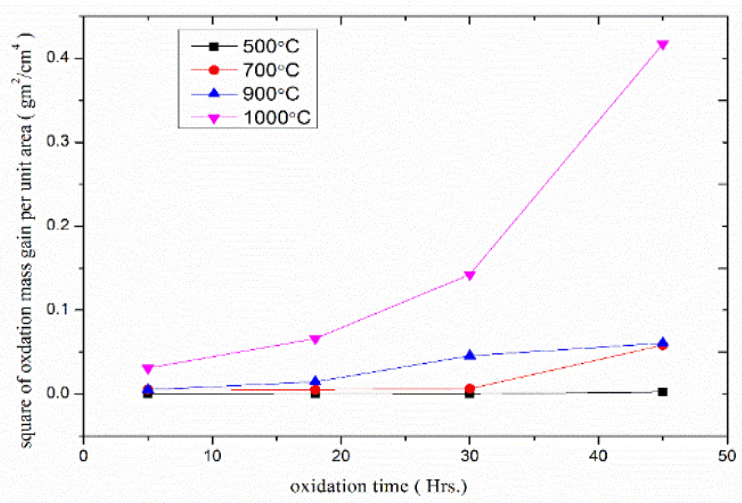

Fig. 10. Correlation between square of oxidation mass gain flux and oxidation time to obtain parabolic rate constant.

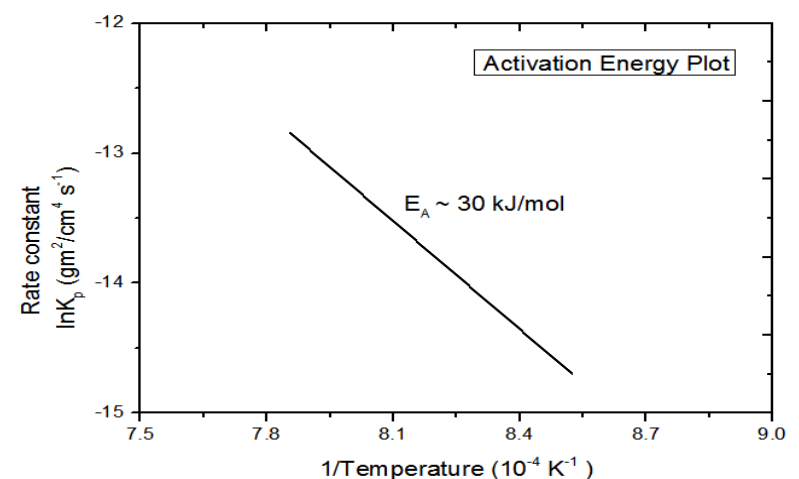

Fig. 11. Activation energy plot for oxidation at higher temperature

The activation energy corresponds to the formation of ferrous oxide over the surface. This value is closer to the value reported by (Grosnever and Kobe, 2005) for low temperature oxidation of iron in oxygen and water vapor i.e. $32 \mathrm{~kJ} / \mathrm{mol}$. At temperature greater than $700^{\circ} \mathrm{C}$, the rate of oxidation is triggered to a higher rate, causing activation energy to decrease considerably. This is also evident from the fact that the oxide thickness and mass gain is linear till $700^{\circ} \mathrm{C}$, but attained a parabolic trend after it. Also, porous nickel oxide structure in as-coated specimen opens up the path of inward and outward diffusion of oxide and ferrous ions respectively with nickel also taking part through point defect reactions.
An adherent coating of Ni-mullite of $110 \mu \mathrm{m}$ thickness was developed by $\mathrm{HVOF}$ process and subjected to oxidation at various temperatures in the range of $500-1000^{\circ} \mathrm{C}$ resulting oxide zones growth of $216-1527 \mu \mathrm{m}$ with increase in the oxidation temperature. It is observed that there is an inward diffusion of oxygen atoms along with little of nickel and aluminum and outward diffusion of iron atoms evident from the absence of nickel from the XRD and EDAX analysis of surface of the oxidized samples. Due to the presence of porous nickel oxide in the Ni-30mullite coating the diffusion is easily facilitated and tends to aggravate at higher temperature and durations, and the oxidation tends to follow a parabolic trend with $1000^{\circ} \mathrm{C}$ oxidised sample showing strong parabolic character. The outward diffusion of ferrous ions causes aggregation of vacancy defects, causing formation of cracks and pores, and with increase in temperature, this oxidation front keeps increasing, thereby the top surface gets piled up more by diffused ferrous atoms. Activation energy corresponding to formation of ferrous oxide over surface is $30 \mathrm{~kJ} / \mathrm{mol}$ for the magnitude of oxidation temperature going beyond $900^{\circ} \mathrm{C}$.

\section{ACKNOWLEDGEMENT}

The authors would like to thank Director, NAL, and Head, SED for their support and encouragement. The authors express their gratitude to Dr.S.K Singh of CSIR-IMMT, Bubaneshwar, INDIA for synthesizing the mullite particles. Authors would like to extend their thanks to Mr. Siju, Mr. praveen, Mr. Srinivas for their assistance rendered in the characterization of the coatings.

\section{REFERENCE}

[1] Tsai, H. L., \& Tsai, P. C. (1995). Performance of laserglazed plasma-sprayed (ZrO2-12wt.\% Y2O3)/(Ni-22wt.\% Cr-10wt.\% Al-1wt.\% Y) thermal barrier coatings in cyclic oxidation tests. Surface and Coatings Technology, 71(1), pp. 53-59.

[2] Sarikaya, O. (2005). Effect of some parameters on microstructure and hardness of alumina coatings prepared by the air plasma spraying process. Surface and Coatings Technology, 190(2-3), pp. 388-393.

[3] Khor, K. A., \& Gu, Y. W. (2000). Thermal properties of plasma-sprayed functionally graded thermal barrier coatings. Thin Solid Films, 372(1-2), pp. 104-113.

[4] Kumar, R., Cietek, D., Jiang, C., Roth, J., Gell, M., \& Jordan, E. H. (2018). Influence of microstructure on the durability of gadolinium zirconate thermal barrier coatings using APS \& SPPS processes. Surface and Coatings Technology, 337, pp. 117-125.

[5] Ghosh, D., Mukherjee, S., Das, S., \& Mitra, S. K. (2016). 


\section{International Journal of Engineering Applied Sciences and Technology, 2019 \\ Vol. 4, Issue 4, ISSN No. 2455-2143, Pages 162-168 \\ Published Online August 2019 in IJEAST (http://www.ijeast.com)}

Effect of yttria (Y 2 O 3) coating for high temperature oxidation resistance of $9 \mathrm{Cr}-1 \mathrm{Mo}$ steel. Protection of Metals and Physical Chemistry of Surfaces, 52(4), pp. 737-743

[6] Wu, J., Guo, H. B., Zhou, L., Wang, L., \& Gong, S. K. (2010). Microstructure and thermal properties of plasma sprayed thermal barrier coatings from nanostructured YSZ. Journal of Thermal Spray Technology, 19(6), pp. 1186-1194.

[7] Marcinauskas, L. (2010). Deposition of alumina coatings from nanopowders by plasma spraying. Journal of Materials Science (MED ZIAGOTYRA), 16, pp. 47-51.

[8] An, Y., Zhao, X., Hou, G., Zhou, H., Chen, J., \& Chen, J. (2014). Tribological and thermal properties of mullite coating prepared by atmospheric plasma spraying. Journal of thermal spray technology, 23(3), pp. 410-419.

[9] Lima, R. S., \& Marple, B. R. (2006). From APS to HVOF spraying of conventional and nanostructured titania feedstock powders: a study on the enhancement of the mechanical properties. Surface and Coatings Technology, 200(11), pp. 3428-3437.

[10] Prasad, G., Chakradhar, P. S., R \& Srivastava, M., (2017). Development and Characterization of Ni-YSZ Coating on Stainless Steel by HVOF Process. International Journal of Engineering and Technical Research. 06, pp. 263-266.

[11] Pham, H. V., \& Nanko, M. (2016). High-Temperature Oxidation of Nickel-Dispersed Mullite Composites in Air. Materials Transactions, 57(9), pp. 1535-1538.

[12] Erler, F., Jakob, C., Romanus, H., Spiess, L., Wielage, B., Lampke, T., \& Steinhäuser, S. (2003). Interface behaviour in nickel composite coatings with nano-particles of oxidic ceramic. Electrochimica Acta, 48(20-22), pp. 3063-3070.

[13] Citra, A., Chertihin, G. V., Andrews, L., \& Neurock, M. (1997). Reactions of laser-ablated nickel atoms with dioxygen. Infrared spectra and density functional calculations of nickel oxides $\mathrm{NiO}, \mathrm{ONiO}, \mathrm{Ni2O} 2$, and $\mathrm{Ni2O}$, superoxide $\mathrm{NiOO}$, peroxide $\mathrm{Ni}(\mathrm{O} 2)$, and higher complexes in solid argon. The Journal of Physical Chemistry A, 101(17), pp. 3109-3118.

[14] Nanko, M. (2005). High-temperature oxidation of ceramic matrix composites dispersed with metallic particles. Science and Technology of Advanced Materials, 6(2), pp. 129-134.

[15] Kim, S. D., Moon, H., Hyun, S. H., Moon, J., Kim, J., \& Lee, H. W. (2006). Performance and durability of Nicoated YSZ anodes for intermediate temperature solid oxide fuel cells. Solid State Ionics, 177(9-10), pp. 931938.

[16] Srivastava, M., Muniprakash, M., \& Singh, S. K. (2014). Synthesis of fused mullite and its use in multifunctional nickel based composite coating. Surface and Coatings Technology, 245, pp. 148-155.

[17] Pieraggi, B. (1987). Calculations of parabolic reaction rate constants. Oxidation of metals, 27(3-4), pp 177-185.

[18] Monceau, D., \& Pieraggi, B. (1998). Determination of parabolic rate constants from a local analysis of mass-gain curves. Oxidation of metals, 50(5-6), pp. 477-493.

[19] Grosvenor, A. P., Kobe, B. A., \& McIntyre, N. S. (2005). Activation energies for the oxidation of iron by oxygen gas and water vapour. Surface Science, 574(2-3), pp. 317321. 